
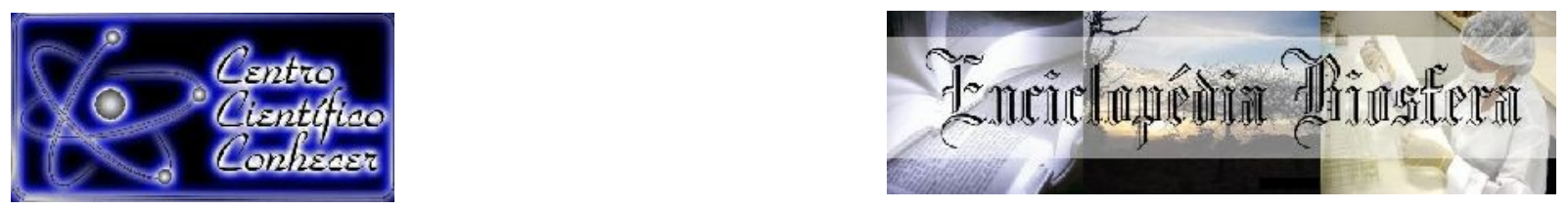

\title{
POTENCIALIDADES DE GERENCIAMENTO DA PRODUÇÃO E TRATAMENTO DE EFLUENTES EM UMA INDÚSTRIA DE PAPEL NA REGIÃO METROPOLITANA DE BELÉM, PA
}

\footnotetext{
Immanuele Rodrigues de Oliveira ${ }^{1}$, Andrea Fagundes Ferreira Chaves ${ }^{2}$, Lana Gabriela Pardal de Andrade ${ }^{3}$, Mário Diego Rocha Valente ${ }^{4}$.

${ }^{1}$ Bacharel em Engenharia Ambiental pela Universidade do Estado do Pará, Belém-PA, Brasil. Email: manuroliveira1@gmail.com.

${ }^{2}$ Dra em Gestão em Saúde Ambiental, Docente da Universidade do Estado do Pará, Belém-PA, Brasil.

${ }^{3}$ Graduanda em Engenharia Ambiental pela Universidade do Estado do Pará, Belém-PA, Brasil.

${ }^{4}$ Bacharel em Estatística pela Universidade Federal do Pará (UFPA), Mestre em Ciências Ambientais pela Universidade Federal Rural da Amazônia (UFRA) Belém-PA, Brasil.
}

\section{Recebido em: 15/11/2020 - Aprovado em: 15/12/2020 - Publicado em: 30/12/2020 DOI: 10.18677/EnciBio_2020D30}

\begin{abstract}
RESUMO
A atividade industrial é de suma importância para as macroeconomias. Segundo dados da Confederação Nacional da Indústria (CNI), em 2018, os processos de fabricação no Brasil contribuíram com $22 \%$ do Produto Interno Bruto (PIB). Dentre as indústrias que mais têm se destacado nos últimos anos, ressalta-se o setor da celulose, dentro do segmento a vertente do papel tissue é o que tem alavancado o setor em detrimento de outros tipos de papéis. Lustosa et al., (2017) afirmam, entretanto, que existe um tradeoff entre o aumento de produção e a preservação ambiental, visto que é característico do segmento uma grande demanda por recursos hídricos, que geram quantidades proporcionais de efluentes contendo substâncias prejudiciais ao recurso hídrico receptor. O objetivo do estudo foi contribuir com o gerenciamento de efluentes em uma indústria de papel tissue na cidade de Belém-PA, localizada na sub bacia do canal São Joaquim. A pesquisa seguiu a metodologia que Gil (2008) classifica como exploratória e foram aplicadas estatísticas básicas para caracterizar a eficiência da estação, com o uso de quatro parâmetros: $\mathrm{DBO}_{5}, \mathrm{DQO}$, SST e $\mathrm{pH}$, no período de agosto de 2018 a julho de 2019. Tais parâmetros foram comparados com as Resoluções Conama № 430/11 e $357 / 05$. Por meio das análises de gráficos e fluxogramas, foi possível promover a redução de $40 \%$ do consumo de água em gaxetas de bombas e propor outras melhorias, e isto, portanto, justifica a necessidade de mais estudos sobre o tratamento primário de efluentes aliado à contínua busca por práticas mais sustentáveis.
\end{abstract}

PALAVRAS-CHAVE: Indústria de tissue, processo produtivo, tratamento de efluentes. 


\title{
POTENTIALS OF MANAGEMENT OF PRODUCTION AND TREATMENT OF EFFLUENTS IN A PAPER INDUSTRY IN THE METROPOLITAN REGION OF BELÉM, PA
}

\begin{abstract}
Industrial activity is of paramount importance for macroeconomies. According to data from the National Confederation of Industry (CNI), in 2018, manufacturing processes in Brazil contributed 22\% of the Gross Domestic Product (GDP). Among the industries that have stood out the most in recent years, the pulp sector stands out, within the segment the tissue paper aspect is what has leveraged the sector to the detriment of other types of paper. Lustosa et al., (2017) states, however, that there is a trade-off between increased production and environmental preservation, since the segment is characterized by a high demand for water resources, which generate proportional amounts of effluents containing substances harmful to the receiving water resource.The objective of the study is to contribute to the management of effluents in a tissue paper industry in the city of Belém-PA, located in the São Joaquim channel sub-basin. The research followed the methodology that Gil (2008) classifies as exploratory and basic statistics were applied to characterize the efficiency of the station, using 4 parameters: BOD5, COD, SST and pH, from August 2018 to July 2019 These parameters were compared with Conama Resolutions No. 430/11 and 357/05. Through the analysis of graphs and flowcharts, it was possible to promote a $40 \%$ reduction in water consumption in pump gaskets and propose other improvements, and this, therefore, justifies the need for further studies on the primary treatment of effluents combined with continuous search for more sustainable practices.
\end{abstract}

KEYWORDS: Tissue industry, production process, wastewater treatment.

\section{INTRODUÇÃO}

A atividade industrial é de suma importância para o desenvolvimento da economia de um País. Por meio desse setor, existe geração de emprego, renda e desenvolvimento de novas tecnologias. Segundo dados da Confederação Nacional da Indústria (CNI, 2018), a participação industrial foi de 1,3 trilhões para a economia brasileira, e sua participação foi de $22 \%$ no produto interno bruto (PIB).

Lustosa et al., (2017) destacam que a industrialização, pelo aumento do uso de recursos naturais, energia, geração de resíduos e lançamento de efluentes, durante o processo produtivo, culmina em um ponto no qual o crescimento da produção implica em aumento do risco de degradação ambiental, isto é, existe um trade-off entre esse crescimento e a preservação ambiental. Deste modo, quanto maior o volume de fabricação, maiores as chances de desastres e crimes ambientais, que podem acarretar multas, embargos, diminuição das vendas e do valor acionário da empresa.

Quanto ao setor de papel e celulose, este apresentou um aumento significativo nas produções, devido aos investimentos em pesquisa e tecnologia, e devido ao crescimento da China enquanto mercado consumidor (MARQUES, 2016). Segundo estudos realizados em 2019 pelo DEPEC-Departamento de Pesquisa e Estudos Econômicos do Banco Bradesco, desde 2014 o setor de papel apresenta crescimento constante anual de exportação, apresentando 1846 mil toneladas de papel, em 2014 até a marca de 2114 mil toneladas em 2017. 
Quando se refere à relação da atividade com o meio ambiente, alguns aspectos ambientais são observados, como a grande demanda por recursos hídricos, que geram quantidades proporcionais de efluentes, além da demanda por recursos naturais e produção de resíduos (PADOVANI;FERREIRA, 2020).

A geração de resíduos e emissões também são citadas como importantes aspectos ambientais ligados à indústria de papel e celulose, em Padovani e Ferreira (2020), as indústrias estudadas que integram a produção de papel e celulose alcançaram uma eficiência na sustentabilidade de apenas $60 \%$. O segmento de tissue é a área de produção de papéis para bens de consumo, portanto a matéria prima advém de celulose, mais nobre, e aparas, que são papéis reciclados. Quando usados esses últimos, a carga de poluição dentro do efluente é maior.

Dentre os exemplos mais importantes de tissue é possível citar o papel higiênico, guardanapo, toalhas e lenços de papel. Entretanto, o segmento tissue não se restringe à fabricação de papéis, engloba uma variedade de outros produtos, como fraldas, absorventes femininos e lenços umedecidos infantis. O Instituto Brasileiro de Árvores (IBA) afirma que o setor de tissue representa o terceiro maior segmento dentro da indústria de papel e celulose, ficando apenas atrás de embalagens e papéis de imprimir e escrever (IBA, 2016).

No setor de papeis para bens de consumo, o maior problema de poluição é causado principalmente pelos materiais em suspensão, substâncias orgânicas dissolvidas e contaminantes tóxicos e potencialmente tóxicos. Segundo Castro e Rodrigues (2016) as exigências legais e a pressão social para preservação do meio ambiente fazem com que as indústrias optem por tecnologias que vão além das exigências legais, e incorporem o fator socioambiental em seu processo de gestão.

O objetivo deste estudo foi conhecer a gestão de efluentes em uma indústria de tissue na Região Metropolitana de Belém e contribuir para a otimização do processo de produção, tratamento e disposição final.

\section{MATERIAIS E MÉTODOS}

A empresa estudada localiza-se na cidade de Belém, região nordeste do Estado do Pará. O clima local de acordo com a classificação climática de Köppen e Geiger é determinado como Af, clima tropical chuvoso durante o ano todo. O empreendimento está inserido na sub bacia do canal São Joaquim, maior canal de Belém, possuindo $8,96 \mathrm{~km}$ de extensão e uma área total de $31,28 \mathrm{~km}^{2}$. A sub bacia faz parte da maior bacia urbana da cidade, bacia do Una, localizada entre as coordenadas geográficas $01^{\circ} 22^{\prime} 0,40^{\prime \prime} S$ e $01^{\circ} 27^{\prime} 21,04^{\prime \prime}$; ; e 48²6'11,53”W e 4828'27,56” W e abrange 20 bairros da região metropolitana de Belém.

O empreendimento possui uma área total 37.694,68 $\mathrm{m}^{2}$, destes, $26.910,38 \mathrm{~m}^{2}$ são de área construída. A fábrica funciona $24 \mathrm{~h}$, em turnos de $8 \mathrm{~h}$, revezamento $6 \times 2$. Atua em média, com 700 funcionários, com atividade desenvolvida pelo empreendimento classificada pela resolução AD REFERENDUM do Conselho Estadual de Meio Ambiente (COEMA) n. 117 de 25 de novembro de 2014, como "fabricação de papel e papelão com AUM de 26.910,38, portanto porte D-II.

A pesquisa seguiu a metodologia de Gil (2008). Para explorar e conhecer as etapas de produção de efluente na empresa inicialmente houve o contato com o responsável pelo processo produtivo. A partir da autorização, todas as etapas de 
produção foram acompanhadas, e foram montados fluxogramas de produção do fluxo de processo do pulper da Máquina de papel (MP), Preparação da massa e consumo de água fresca, essas etapas foram escolhidas com base no critério de maior desperdício de água e problemas ambientais encontrados.

Ainda para explorar os processos da empresa houve a caracterização do efluente produzido. Para caracterizar foram selecionados os parâmetros Demanda Bioquímica de Oxigênio ( $\mathrm{DBO}_{5}$ ), Demanda Química de Oxigênio (DQO), Sólidos Suspensos Totais (SST) e Potencial Hidrogeniônico (pH).

Foi realizado o perfil mensal destes parâmetros, por um período de 12 meses, em conjunto com a empresa em estudo. As coletas de amostras foram realizadas semanalmente, totalizando 58 coletas, realizadas na entrada e saída da Estação de Tratamento de Efluentes (ETE). Para o parâmetro $\mathrm{pH}$ foram realizadas 69 medições, a fim de obter melhor controle da variação desse parâmetro, o qual tem maior capacidade de variação temporal.

As amostras foram enviadas ao laboratório credenciado, o qual realizou as análises de acordo com Apha (2017) os resultados obtidos foram submetidos a análise estatística descritiva quantitativa. A fim de julgar a eficiência da ETE foram construídos gráficos de caracterização do efluente produzido a montante e jusante da ETE e comparados com a Resolução CONAMA n.357/05 (BRASIL, 2005) e Resolução CONAMA n.430/11 (BRASIL, 2011). Para compreender melhor o funcionamento da ETE foi desenvolvido o croqui das etapas de tratamento, já que a empresa não possui planta baixa do local, e além disso foram acompanhadas as etapas de tratamento para análise de possíveis oportunidades de melhoria na dinâmica de tratamento.

Após as etapas sobreditas, ocorreu a aplicação do método Gap-analysis, também conhecido como análise de lacuna, que é um método utilizado para avaliação do desempenho real da empresa diante de seu potencial. De acordo com Picolo et al., (2016) para solucionar a situação é necessário entender o estado atual e onde é necessário melhorar, como mostra a figura 1.

FIGURA 1-Estrutura geral para análise e solução de gaps.

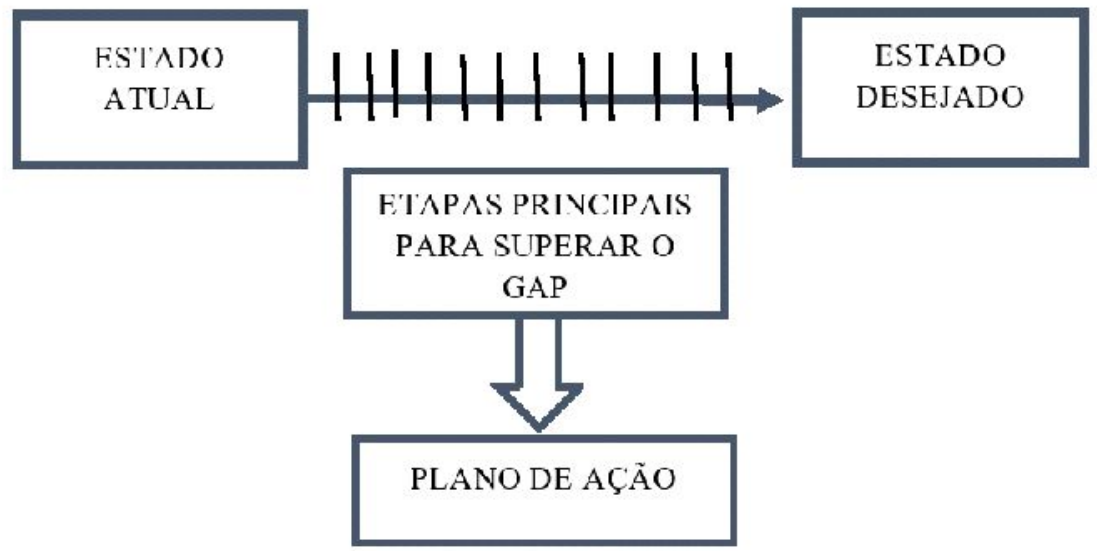

Fonte: Rebouças, (1999). 
Na etapa de aplicação da Gap Analysis (Análise de Falhas) foram analisados equipamentos que necessitavam de manutenção, que causavam desperdício de água; Pontos de contaminação que poderiam ser evitados, e ainda as possibilidades de otimizar o processo de tratamento na ETE. Para conseguir chegar nessas análises utilizou-se da metodologia 6M's, também conhecida como diagrama de Ishikawa ou Espinha de peixe (ISHIKAWA, 1993). Neste método, existem seis categorias de análise, e particularmente foi incluído o sétimo M (monetário). Os M's são: Mão de obra, método, métricas, máquinas, materiais, minutos (tempo necessário para atingir o objetivo) e monetário.

\section{RESULTADOS E DISCUSSÕES}

A resolução Conama № 430/11 estabelece padrões de lançamento de efluente em corpos hídricos segundo a classificação do corpo receptor. Além disso, é responsabilidade do empreendimento monitorar os parâmetros de qualidade desse recurso hídrico, que é regulamentado pela resolução Conama n. 357/05 (BRASIL, 2005). Isso significa que ter como base os padrões estabelecidos por essas duas resoluções é de suma importância para o estudo em questão, visto que como será visto posteriormente, nos resultados expressos em tabela e gráficos, a comparação dos resultados obtidos com os padrões estabelecidos possibilitou o entendimento das características físico-químicas do efluente produzido pela empresa.

- Processo produtivo e a Produção de efluentes na indústria estudada

Para demonstrar o perfil de fabricação do empreendimento foram levantados produtos e seu percentual de fabricação dos meses de janeiro a junho de 2019. Foram classificadas quanto ao tipo de matéria-prima, 100\% celulose, aparas e mistura entre aparas e celulose. De acordo com a tabela 1:

TABELA 1-Percentual de fabricação semestral de cada tipo de produto fabricado

\begin{tabular}{l|c|c|c|c|c|c}
\hline & jan/19 & $\mathbf{f e v} / \mathbf{1 9}$ & mar/19 & abr/19 & mai/19 & jun/19 \\
\hline 100\% CELULOSE (\%) & 38,84 & 41,79 & 36,83 & 40,65 & 69,18 & 45,80 \\
\hline $\begin{array}{l}\text { APARAS+CELULOSE } \\
\text { (\%) }\end{array}$ & 46,02 & 39,41 & 50,60 & 47,07 & 11,99 & 47,25 \\
\hline APARAS (\%) & 15,17 & 18,80 & 12,54 & 12,28 & 18,83 & 6,95 \\
\hline
\end{tabular}

Fonte: Autores, (2019)

Quando a fabricação tem como matéria-prima fibras virgens - $100 \%$ celulose, o efluente apresenta característica de concentração menos poluente. Quanto maior a incorporação de aparas na "receita", maior a carga de poluente e a dificuldade para tratar o efluente e encaminhá-lo para o corpo receptor.

Desse modo, foi possível observar que, majoritariamente, a produção envolve o uso de aparas, o que já remete a um maior trabalho e talvez maior custo com o processo de tratamento do efluente, por isso a importância de saber até que ponto reutilizar torna-se uma vantagem econômica e também ambiental. Existe o destaque para os meses de maio e junho, com maior volume de produção à base de celulose, que já representa a transição para o segundo semestre quando os produtos com fibra virgem apresentam um incremento nas vendas.

Os meses de março, abril e junho apresentaram a menor quantidade de produto ENCICLOPÉDIA BIOSFERA, Centro Científico Conhecer - Jandaia-GO, v.17 n.34; p. 397 2020 
feito totalmente com aparas. O mês de maio foi o único do semestre, no período em estudo, que teve maior participação de celulose do que produtos com algum percentual de papel reciclado. A partir do conhecimento dos produtos da empresa, foram desenvolvidos os fluxogramas de produção, apresentados nas figuras 2 e 3 .

FIGURA 2 - Fluxo de processo do pulper da máquina de papel.

\section{FLUXO DE PROCESSO PULPER MP3}



Legenda: Conjunto motor bomba.

Fonte: Autores, (2019).

No pulper da Máquina de Papel (MP) utiliza água recuperada, independente se o produto é a base de celulose ou de aparas, isso porque a concentração de fibras remanescentes pode ser utilizada nas próximas etapas de fabricação. No entanto, a reutilização das fibras na máquina acaba por elevar a concentração de produtos no efluente e decomposição das fibras, e esse é um dos principais motivos para os expressivos valores de DBO e DQO.

A figura 3 apresenta o caminho percorrido pela massa. Primeiramente os resíduos incorporados a matéria prima são retirados, tais como grampos, clips, poeira, entre outros que prejudicam a formação do papel, isso é feito entre o tanque 7 e o tanque 1. Também é na preparação de massa que parâmetros de qualidade do papel são definidos, dentre estes: gramatura, consistência, espessura, resistência à tração e hand-few. Nessa etapa foram identificadas importantes oportunidades de melhoria, devido aos pontos de desperdício de água no processo. 
FIGURA 3- Preparação de massa.

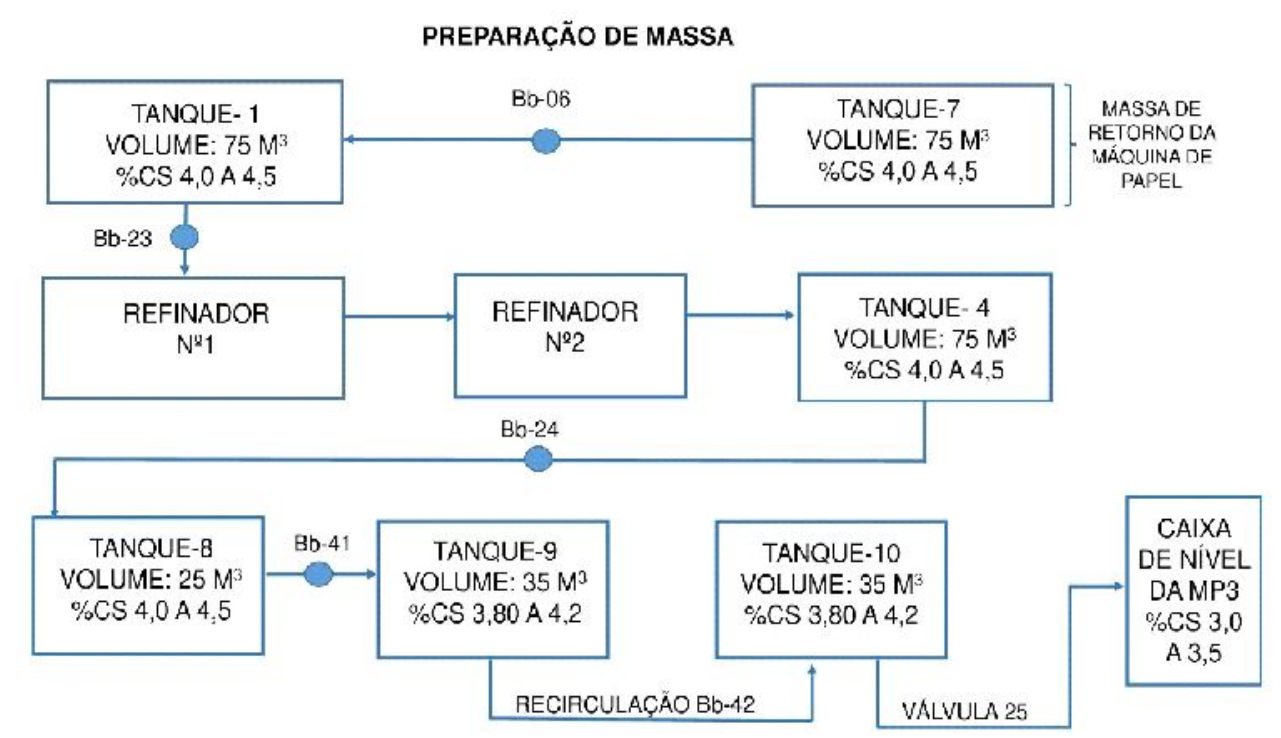

Legenda: Conjunto motor bomba.

Fonte: Autores, (2019)

A água fresca (figura 4) utilizada na fabricação advém de três poços, a água dos poços é encaminhada para estação de tratamento de efluentes, onde é realizada a aeração com intuito de retirar a concentração de ferro excedente e depois decantação. Em seguida, a água é armazenada em um reservatório com volume de $16.8 \mathrm{~m}^{3}$. Essa água é utilizada em seis tanques diferentes, para refino da massa, diluição de químicos, limpeza da máquina, pontos estratégicos de emergência contra incêndios e em bicos de chuveiro para diminuir a temperatura do papel.

FIGURA 4- Consumo de água fresca

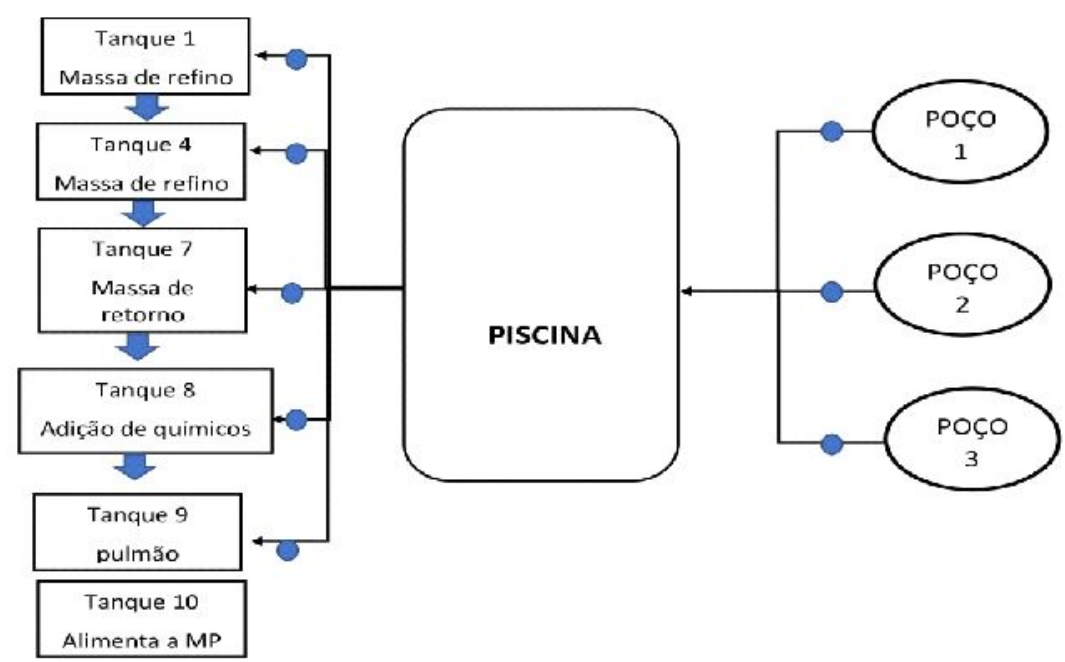

Fonte: Autores, (2019) 
O consumo exagerado de água advinda dos poços é um dos principais problemas que tange a relação entre fabricação e meio ambiente. As principais atuações da água fresca são em: gaxetas de bombas, chuveiros de químicos, trocadores de calor e aditivos de telefeltros. Desses, os trocadores de calor são pontos nos quais há mais desperdício de recurso hídrico, visto que são canalizações que passam no entorno de mancais, que são peças de ligação de engrenagem por onde circula óleo aquecido, vindo de centrais de óleo.

Esses mancais são dispositivos de rolamentos mecânicos adotados na máquina e projetados para suportar cargas aplicadas em um eixo enquanto ele gira. Por ser um componente fixo em contato com outro que se movimenta, a escolha do mancal tem relação direta com o atrito gerado e com a eficiência da transferência de energia mecânica. A quantidade de água usada para resfriamento é elevada e encaminhada para estação.

Outro ponto observado foi a utilização em excesso de água fresca em gaxetas de bombas na MP3. É necessário o uso da água fresca devido a temperatura inferior à da água recuperada para resfriar as gaxetas das bombas. No entanto, devido à vazão maior que o necessário e aos níveis de manutenção, o desperdício de água é significativo. Já as águas drenadas da tela de formação do papel, a água do polo de sucção, água dos chuveiros de filtro, bombas de fino se reúnem no tanque 12, para serem usadas na preparação de massa, a água remanescente é encaminhada para o krofta onde passa por tratamento físico-químico: floculação/coagulação, e posteriormente é devolvida para o processo, encaminhada diretamente para a preparação de massa.

\section{- Características físico-químicas dos efluentes produzidos}

Para caracterizar o efluente produzido, bem como analisar eficiência alcançada pela ETE, apresenta-se (tabela 2) a estatística descritiva de um período de 12 meses de estudo, com um total de 58 amostras analisadas.

TABELA 2 - Resumo Estatístico das medidas

\begin{tabular}{|c|c|c|c|c|c|c|c|c|c|}
\hline \multirow{2}{*}{\multicolumn{2}{|c|}{ Estatística }} & \multicolumn{2}{|c|}{ DBO (mg/l) } & \multicolumn{2}{|c|}{$\mathrm{DQO}(\mathrm{mg} / \mathrm{l})$} & \multicolumn{2}{|c|}{ SST (mg/l) } & \multicolumn{2}{|c|}{$\mathrm{pH}$} \\
\hline & & Entrada & Saída & Entrada & Saída & Entrada & Saída & Entrada & Saída \\
\hline \multicolumn{2}{|c|}{ Média } & 87,06 & 75,07 & 460,29 & 166,49 & 543,41 & 47,43 & 7,66 & 7,56 \\
\hline \multicolumn{2}{|c|}{ Moda } & 40 & 14 & 149 & 250 & 20 & 7 & 8 & 8 \\
\hline \multicolumn{2}{|c|}{$\begin{array}{l}\text { Desvio } \\
\text { Padrão }\end{array}$} & 60,661 & 80,655 & 454,305 & 179,445 & 608,125 & 145,482 & 0,344 & 0,375 \\
\hline \multicolumn{2}{|c|}{ Assimetria } & 1,670 & 4,313 & 1,844 & 1,782 & 1,164 & 6,880 & $-2,048$ & $-4,328$ \\
\hline \multicolumn{2}{|c|}{ Kurtosis } & 3,937 & 24,405 & 2,896 & 3,172 & 0,758 & 49,216 & 31,136 & 30,605 \\
\hline \multicolumn{2}{|c|}{ Mínimo } & 9,97 & 2,21 & 56,5 & 10,4 & 2,0 & 1,5 & 4,1 & 4,0 \\
\hline \multicolumn{2}{|c|}{ Máximo } & 326 & 243 & 1876 & 819 & 2580 & 1074 & 9 & 9 \\
\hline \multirow{3}{*}{$\begin{array}{l}\text { Qua } \\
\text { rtis }\end{array}$} & $25 \%$ & 46,60 & 35,55 & 160,70 & 51,70 & 63,00 & 9,25 & 7,58 & 7,51 \\
\hline & $50 \%$ & 69,16 & 59,09 & 304,00 & 83,00 & 246,00 & 16,50 & 7,67 & 7,61 \\
\hline & $75 \%$ & 119,31 & 76,78 & 593,50 & 251,00 & 1044,00 & 36,75 & 7,79 & 7,71 \\
\hline
\end{tabular}

Fonte: Modificado de Suzano, (2019). 
Ao realizar uma análise descritiva das medidas, verificou-se que a relação entre DQO/DBO foi de 5 na entrada, e uma relação de 2 na saída da ETE. A relação DQO/DBO (BRAILE;CAVALCANTI, 1979), indica que a fração recalcitrante é alta. Apesar da redução desta relação ser bastante significativa, a eficiência na remoção de DBO foi de apenas $13 \%$. Já quando se observou a DQO a eficiência alcançada foi de $63 \%$, o que reafirma a natureza predominantemente recalcitrante deste efluente.

Como a média de entrada da DBO correspondia a 87,06 mg/L, foi maior do que a mediana $69,16 \mathrm{mg} / \mathrm{L}$, e maior que a moda $40 \mathrm{mg} / \mathrm{L}$, então, a distribuição da DBO é assimétrica, positiva à direita, ou seja, a assimetria é positiva quando predominam os valores mais altos das observações, de modo a concentrar os valores muito acima do esperado, podendo causar diversos problemas na prática. Com base nos quartis, verificou-se que $75 \%$ das amostras coletadas para DBO na entrada estavam com valores em torno de $119,31 \mathrm{mg} / \mathrm{L}$, acima da média e do limite superior.

A figura 5 apresenta a variação de $\mathrm{DBO}_{5}$ na entrada e na saída da $\mathrm{ETE}$, em que se destacam os menores valores registrados de $\mathrm{DBO}_{5}$ de $9,97 \mathrm{mg} / \mathrm{L}$ para entrada e 2,21 $\mathrm{mg} / \mathrm{L}$ para saída. De modo que, apenas $34,43 \%$ das amostras de saída coletadas estavam dentro da legislação (Resolução Conama 357/05, corpo hídrico de água doce classe 2). DBO é um dos parâmetros mais importantes da legislação e expressa a qualidade do tratamento aplicado, em termos de remoção de material orgânico.

FIGURA 5- Demanda Bioquímica de Oxigênio/Dados de Entrada e Saída
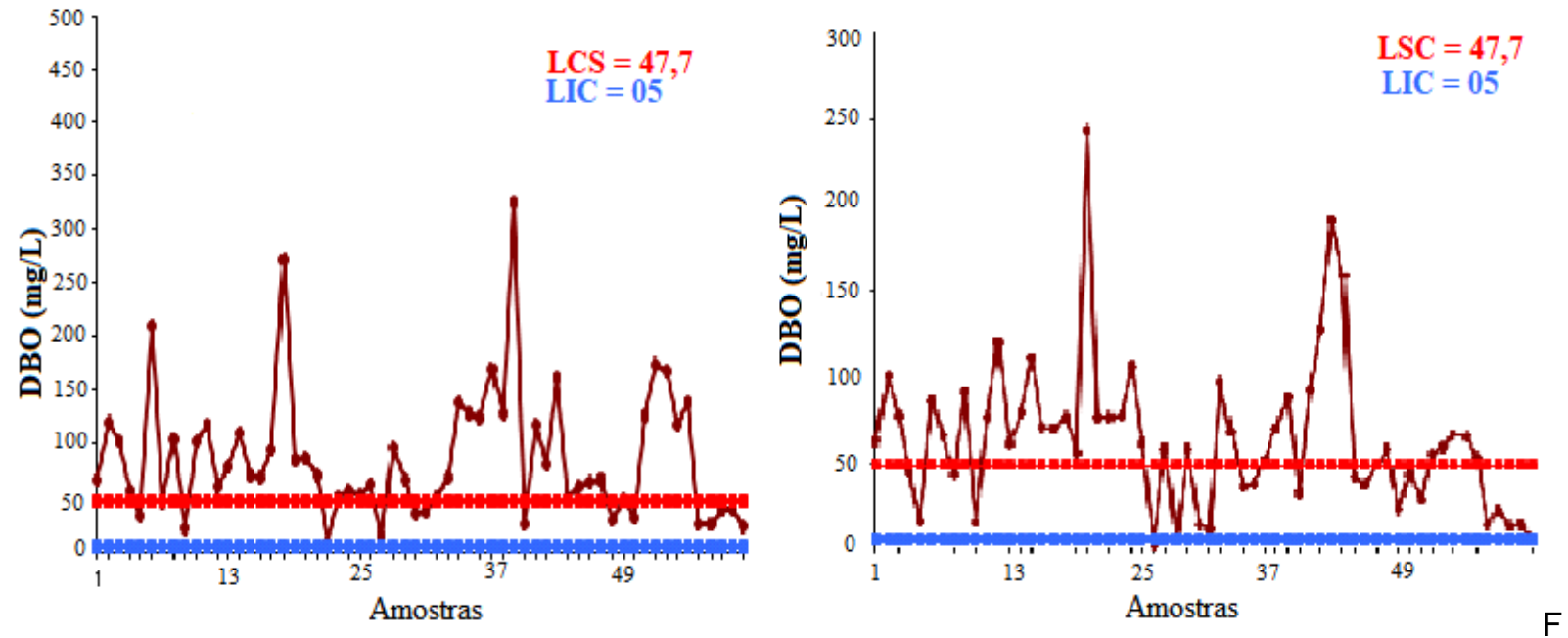

Fonte: Autores, (2019)

Quanto aos valores de DQO, a tabela 2 destaca que a moda foi $149 \mathrm{mg} / \mathrm{l}$ para entrada, e $250 \mathrm{mg} / \mathrm{l}$ para saída. A moda representa o conjunto de valores que mais se repetiram no estudo, assim, percebe-se que, frequentemente, houve um acréscimo de DQO na saída da ETE, devido ao acúmulo de material orgânico de difícil degradabilidade, proveniente da matéria prima. 
FIGURA 6 - Demanda Química de Oxigênio/Dados de Entrada e Saída


Fonte: Autores, (2019)

A figura 6 mostra a variação de DQO na entrada e saída da ETE, em que se destaca importante variação deste parâmetro na entrada, obtendo-se um valor mínimo nas 58 amostras, de 56,5 mg/l e máximo de 1876 mg/l. Esta variação é negativa ao tratamento biológico.

Quanto aos valores de SST, a tabela 2 mostra que tanto as médias de entrada (543, $41 \mathrm{mg} / \mathrm{L})$ quanto de saída $(47,43 \mathrm{mg} / \mathrm{L})$ apresentam valores fora dos padrões de lançamento (Resolução Conama 357/05). Os níveis de SST encontrados apontam para limitações do processo de decantação e remoção de material orgânico, na ETE estudada.

FIGURA 7 -pH/Dados de Entrada e Saída
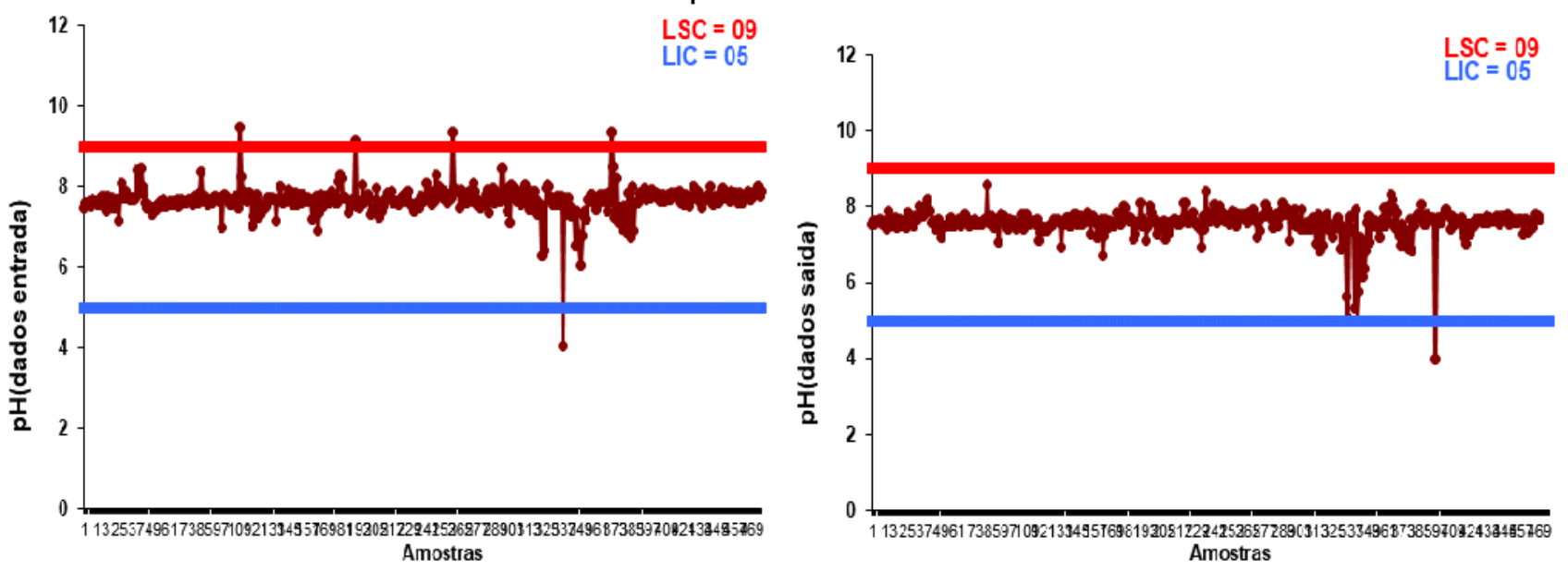

Fonte: Autores, (2019).

Analisando os valores de $\mathrm{pH}$ encontrados no estudo, destaca-se a figura 7, em que os valores de $\mathrm{pH}$ estiveram entre 7 e 8 . A Resolução CONAMA 357/05, estabelece que águas de classe 2, são destinadas, entre outros, à preservação da vida aquática 
(artigo $4^{\circ}$ ), o que restringe o despejo de efluentes industriais, nomeadamente aqueles cujos parâmetros físico-químicos podem causar modificações nos ecossistemas aquáticos.

O resultado de apenas $34,4 \%$ das amostra de DBO na saída estarem dentro da legislação, bem como o frequente acréscimo de DQO nas amostras de saída da ETE, e ainda médias de entrada e saída dos valores de SST fora dos padrões (Resolução Conama 357/05) evidenciam o quanto é importante estudos de caso sobre o tratamento de efluentes dentro do gerenciamento de empresas potencialmente poluidoras, principalmente em Estados como o nosso, onde existe apenas um comitê de bacia hidrográfica $(\mathrm{CBH})$ regulamentado. Sabe-se que os comitês são os responsáveis por estipular a classificação do corpo hídrico. No entanto, na ausência dos $\mathrm{CBH}$, os órgãos de meio ambiente do estado baseiam-se nos parâmetros de rios de água doce classe 2.

Diante da insuficiência de comitês de bacias que auxiliam na classificação dos corpos receptores e ajudam na preservação ambiental, é necessário estudos que evidenciem a importância da análise dos parâmetros dos corpos hídricos receptores, bem como monitoramento dos efluentes que serão lançados nesses corpos.

\section{- Otimização do processo de geração e tratamento dos efluentes}

No presente estudo, foi realizada a elaboração de um quadro para organização de projetos que propõem resoluções de gaps dentro do processo. Para tal, foi adotada a metodologia dos 6 M's que estabelece os seis principais ativos de resolução de falhas, conforme descrito na metodologia deste estudo. O quadro 1 apresenta duas falhas identificadas (gap), e soluções propostas, de acordo com a natureza destas falhas.

QUADRO 1 - Propostas de resolução de gaps por meio da metodologia 6M's

\begin{tabular}{|c|c|c|c|c|c|c|c|}
\hline \multicolumn{8}{|c|}{ Diagrama de Ishikalma para resolução de Gaps } \\
\hline GAP & $\begin{array}{c}\text { Mão de } \\
\text { obra }\end{array}$ & método & máquinas & materiais & $\begin{array}{c}\text { métric } \\
\text { as }\end{array}$ & $\begin{array}{c}\text { minuto } \\
\mathrm{s}\end{array}$ & $\begin{array}{l}\text { monet } \\
\text { ário }\end{array}$ \\
\hline $\begin{array}{l}\text { Contamin } \\
\text { ação de } \\
\text { óleos e } \\
\text { graxas no } \\
\text { efluente }\end{array}$ & $\begin{array}{l}\text { Fabricaç } \\
\text { ão e } \\
\text { manuten } \\
\text { ção }\end{array}$ & $\begin{array}{c}\text { By-pass e } \\
\text { troca de } \\
\text { manutençã } \\
0\end{array}$ & - & $\begin{array}{l}\text { Manguei } \\
\text { ra e } \\
\text { tanque }\end{array}$ & $\begin{array}{c}10 \mathrm{M} \\
\text { de } \\
\text { mangu } \\
\text { eira }\end{array}$ & 240 & $\begin{array}{l}\text { Sem } \\
\text { custo }\end{array}$ \\
\hline $\begin{array}{l}\text { Desperdí } \\
\text { cio de } \\
\text { água por } \\
\text { parte da } \\
\text { operação }\end{array}$ & $\begin{array}{c}\text { Fabricaç } \\
\text { ão }\end{array}$ & $\begin{array}{c}\text { Treinament } \\
\text { o, } \\
\text { conscientiz } \\
\text { ação e } \\
\text { instalação } \\
\text { automática } \\
\text { de válvulas } \\
\text { controlador } \\
\text { as }\end{array}$ & - & $\begin{array}{c}\text { Válvulas } \\
\text { controla } \\
\text { doras de } \\
\text { níveis }\end{array}$ & $\begin{array}{c}3 \\
\text { válvul } \\
\text { as }\end{array}$ & 720 & $\begin{array}{c}\mathrm{R} \$ \\
1000 / \mathrm{u} \\
\text { nidade }\end{array}$ \\
\hline
\end{tabular}

Fonte: Autores, (2019) 


\section{- Propostas de resolução}

No item óleos e graxas que contaminam o efluente, por um critério de custo optou-se por sugerir a implantação de membranas de filtração. De acordo com Bortoluzzi et al. (2020) a nanofiltração por membrana é uma alternativa efetiva para a retirada de materiais com a mesma natureza, visto a eficiência do processo e pouca demanda de área.

A tecnologia de tratamento evoluiu gradualmente dos sistemas de filtros naturais usados no passado para os sistemas baseados em membranas usados na atualidade (LI; VISVANATHAN, 2017). No trabalho realizado por Galvão e Gomes (2018) no qual foi testada a eficiência de MF (microfiltros) e UF (ultrafiltros), que são espécies de membrana de filtração, concluiu-se que para ambas a eficiência para remoção de óleos e graxas em efluentes de uma indústria de lacticínios, foi de $95,89 \%$, quase $100 \%$ de eficiência, evidenciando a proposta de resolução do problema como algo viável e com alto nível de eficácia.

\section{- Propostas de resolução já implementadas}

\section{Redução de cálculo de consumo de água em gaxetas}

Um dos principais pontos observados foi a utilização excessiva de água fresca em gaxetas de bombas na MP. Gaxetas de bombas são caixinhas que ficam na parte de cima das bombas, por meio destas passa água advinda de poços, essa água é naturalmente gelada. É necessário o uso de água fresca devido a temperatura inferior à da água recuperada para resfriar as gaxetas das bombas. As gaxetas precisam vazar, mas não tanto.

De acordo com Braga (2015) os fabricantes fornecem a curva característica ou curva de desempenho para cada bomba, levando em consideração o produto bombeado e dependendo da necessidade, sofrem correções quando aplicadas a fluidos com diferentes densidades e viscosidade. As curvas características das bombas centrífugas apresentam uma faixa de operação de vazão (range de operação) em que a bomba deve trabalhar para obter um funcionamento estável como uma maior vida útil e eficiência.

Para calcular a vazão que passa por uma gaxeta foi retirado o tubo de alimentação e analisado o quanto enchia um frasco em um determinado período de tempo, o mesmo foi feito com a parte da "perda". Essa análise foi aplicada para três gaxetas de bombas e foi aferida a média. No entanto, devido à vazão maior do que o necessário e aos seus níveis de manutenção, foi implementada a redução desse volume de água. O cálculo adotado para determinar o consumo (Q) desses equipamentos foi a média de três vazões mais a média das respectivas perdas $\left(Q_{P}\right)$ multiplicado pelo total de gaxetas $(n)$.

$$
\begin{aligned}
\text { Qtotal }= & {[(\mathrm{Q} 1+\mathrm{Q} 2+\mathrm{Q} 3)]+\left[\left(\mathrm{Q}_{\mathrm{P} 1}+\mathrm{Q}_{\mathrm{P} 2}+\mathrm{Q}_{\mathrm{P} 3}\right) \mathrm{n}\right.} \\
& \mathrm{Qtotal}=638.557,3978 \mathrm{l} / \mathrm{dia}
\end{aligned}
$$

Após a implementação da solução proposta de acordo com a metodologia $6 \mathrm{M}$ descrita na tabela acima, ou seja, adotando, dentro da equipe de operação da indústria, treinamentos e conscientização e ainda introduzindo na linha de produção a instalação automática de válvulas controladoras de níveis, foi possível obter redução de $40 \%$ na vazão. Após a aplicação do método foi feito novamente o mesmo processo e constatouse que a vazão atual das 16 gaxetas foi de 383.134,44 l/dia. 


\section{Reutilização de água dos trocadores de calor de mancais}

Para reutilização da água, foi estimada a vazão de saída de todos os mancais, e multiplicada pelos quatro que existem na MP (Máquina de papel). Juntas correspondem a uma vazão de $2,5 \mathrm{~m}^{3}$ /hora. Para cada uma foi implementado um by-pass (desvio), que alimenta os tanques, onde essa água é reservada e, portanto, passa por resfriamento; Antes da solução esses tanques eram antes desativados. Somado a isso foram colocadas torneiras, nesses tanques, como essa água tem parâmetros adequados, pode ser utilizada para limpeza de parte da área industrial e de equipamentos, de forma a estimular o uso racional da água.

\section{CONCLUSÕES}

Foi possível identificar a relevância do segmento de tissue na indústria brasileira, por meio do crescente nível de produção e crescimento acima da média de outros setores de papel. Diante dessa importância, torna-se imprescindível o desenvolvimento de estudos acerca do tratamento de efluentes nesse tipo de indústria para aprimorar cada vez mais os índices de eficiência e proteção ambiental, visto que os valores analisados dos quatro parâmetros comprovaram o potencial poluidor que essa vertente da economia é capaz. Diante dos estudos levantados, e da modificação de processos de produção torna-se perceptível o empenho e preocupação que a indústria em estudo demonstrou em se adequar aos parâmetros ambientais, para isso faltavam estudos e análises de projeto para compreender o estado atual do sistema e estratégias de custo $x$ benefício para a adequação. Com estudos na área é possível manter o funcionamento de fábricas com geração de emprego, crescimento da economia do País e segurança do meio ambiente para essa e futuras gerações.

\section{REFERÊNCIAS}

APHA, American Public Health Association. Standard methods for the examination of water and wastewater, 22a. ed., Washington: American Public Health Association, 2017.

BORTOLUZZI, A.C.;DALLAGO, R.M.; TRES, M.V.; STEFFENS, J.; ZENI,J.; STEFFENS, C.;; Uso de membrana de microfiltração seguida de ultrafiltração no tratamento de efluente líquido de indústria de soro de leite. Brazilian Journal of Development, v. 6, n. 9, 2020. ISSN 2525-8761. Disponível em: https://www.brazilianjournals.com/index.php/BRJD/article/view/16197. Acesso: 28/10/2020.

BRAGA, R.L. Sistemas de vedação para soluções de bombeamento e desperdício de água, 2015. 2 Disponível em: http://yceumonline.usf.edu.br/salavirtual/documentos/2718.pdf. Acesso em: 02/09/ 2020.

BRASIL. Resolução CONAMA n. 357. Dispõe sobre a classificação dos corpos de água e diretrizes ambientais para o seu enquadramento, bem como estabelece as condições e padrões de lançamento de efluentes, e dá outras providências. Decreto. Brasil, $2005 . \quad$ Disponível em: 
http://www.icmbio.gov.br/cepsul/images/stories/legislacao/Resolucao/2005/res_conama 357_2005_classificacao_corpos_agua_rtfcda_altrd_res_393_2007_397_2008_410_20 09_430_2011.pdf. Acesso em: 21/11/ 2019.

BRASIL. Resolução CONAMA n. 430, de 13 de maio de 2011. Dispõe sobre as condições e padrões de lançamento de efluentes, complementa e altera a Resolução n. 357, de 17 de março de 2005, do Conselho Nacional do Meio Ambiente - CONAMA. Brasil, $2011 . \quad$ Disponível em: http://www2.mma.gov.br/port/conama/legiabre.cfm?codlegi=646. Acesso em: 18/10/2019.

BRAILE, P.M.; CAVALCANTI, J.E.W.A. Manual de tratamento de águas residuárias industriais. In: Manual de tratamento de águas residuárias industriais. Cetesb, 1979.

CASTRO, R. A.; RODRIGUES, J. C. A Responsabilidade Social Corporativa e o relacionamento com as comunidades rurais: o caso da Suzano Papel e Celulose e da Vale, no estado do Maranhão, Nordeste do Brasil. Revista Enciclopédia Biosfera, Goiânia, v. 13, 2016. ISSN 1809-0583. Disponível em: https://www.conhecer.org.br/enciclop/2016a/ciencias\%20sociais/a\%20responsabilidade \%20social.pdf. Acesso: 28/10/2020.

CNI - Confederação Nacional da Indústria, 2018. Disponível em: http://www.portaldaindustria.com.br/cni/estatisticas/. Acesso em: 18/08/2019

DEPEC - Departamento de Pesquisa e Estudos Econômicos do Banco Bradesco, 2019. Disponível em: https://www.economiaemdia.com.br/EconomiaEmDia/pdf/infset_papel_e_celulose.pdf. Acesso em: 18/08/2019.

GALVÃO, D.; GOMES, E. Remoção de nutrientes, microrganismos e matéria orgânica de efluente de indústria de laticínios por processos de separação por membranas. Revista CIATEC - UPF, v.10 (1), p.68-85, 2018. INSS 2176-4565. Disponível em: http://seer.upf.br/index.php/ciatec/article/view/6685. Acesso em: 02/09/2020.

GIL, A. C. Métodos e técnicas de pesquisa social. 6. ed. São Paulo: Editora Atlas, 2008.

IBA - Indústria Brasileira de Árvores. Anuário estatístico da indústria brasileira de árvores: Ano base 2016. São Paulo/ Brasília, 2016. Disponível em:https://www.iba.org/datafiles/publicacoes/pdf/iba-2015.pdf. Acesso em: 20/10/2019.

ISHIKAWA, K. Controle de qualidade total - à maneira japonesa. 2.ed. Rio de Janeiro, Campus, 1993. Disponível em: https://www.scielo.br/scielo.php?script=sci_nlinks\&ref=000165\&pid=S0104530X199800030001000010\&lng=en. Acesso: 18/02/2019. 
LI, L; VISVANATHAN, C. Membrane technology for surface water treatmente: Advancement from microfiltration to membrane bioreactor. Revista Environmental Sci Biotechnol, 2017. 16: 737-760. ISSN 1572-9826. Disponivel em: https://doi.org/10.1007/s11157-017-9442-1. Acesso em: 23/07/2019.

LUSTOSA, J. B.,; BRACARENSE, D.C.; CASTRO, F.M.; BERNARDO, S.C.; SILVA, Q.G.G.; (Org.). Tratamento e aproveitamento de água de lavagem de filtro em estação de tratamento de água. Revista DAE, v. 65, n. 206, 2017. ISSN 0101-6040. Disponível em: http://revistadae.com.br/artigos/artigo_edicao_206_n_1671.pdf. Acesso em: 28/06/2019.

MARQUES, M. I. M. Considerações sobre a expansão da indústria de papel e celulose no Brasil a partir do caso da Suzano Papel e Celulose. Revista GEOgraphia, v. 17, n. 35, p. 120-147, 2016. ISSN 2674-8126. Disponível em: https://periodicos.uff.br/geographia/article/view/13731. Acesso em: 18/08/2019.

PADOVANI, M. P.; FERREIRA, D. H. L. Estudo da aplicação do modelo DEA na avaliação da eficiência das principais indústrias de papel e celulose no Brasil na dimensão ambiental do desenvolvimento sustentável. Revista Gestão \& Sustentabilidade Ambiental, v. 9, n. 1, p. 231-254, 2020. INSS 2238-8753. Disponível em:http://www.portaldeperiodicos.unisul.br/index.php/gestao_ambiental/article/view/720 9. Acesso em: 29/10/20.

PICOLO, J.D., MACHADO, D.D.P.N.; TONTINI, G.; DOCKHORN, M.; GAVA, S.D.; Using Improvement Gap Analysis for the management of trade-offs of operational strategies. Revista Gestão e Produção. [online], v.23, n.1, p.48-59. Epub Sep 29, 2016. ISSN 1806-9649. https://doi.org/10.1590/0104-530X1660-14. Acesso em: 18/07/2019.

REBOUÇAS, A.C.; BRAGA, J.; BENEDITO, P.F.; TUNDISI, J.G. Águas doces no Brasil: capital ecológico, uso e conservação. [S.I: s.n.], 1999.

RESOLUÇÃO AD REFERENDUM COEMA № 117, DE 25 DE NOVEMBRO, 2014. Disponível em: https://www.semas.pa.gov.br/legislacao/files/pdf/235.pdf. Acesso em: 18/08/2019. 